\title{
The Practical Application of Educational Psychology in College Education
}

\author{
Li Ting \\ Shaanxi Academy of Governance, Xi'an ,710068
}

Keywords: Educational psychology; College education; Psychological quality; Learning ability

\begin{abstract}
The good psychological state of college students does not only help to improve the quality of teaching, but also promotes students' own learning ability. At present, educational psychology has been widely used in teaching practice in colleges and universities. It is true that high-efficiency teaching has never been achieved by relying on mandatory management tools and indoctrination methods. Therefore, teachers should actively master the psychological state of learning of students and help them according to their actual needs in teaching process in order to achieve a good teaching effect.
\end{abstract}

\section{The Main Advantages of Educational Psychology in Teaching}

Under the current national conditions, China's education policy is gradually shifting from exam-oriented education to quality education. The quality of teachers should be the precondition and primary goal for quality education. In this case, we may require students' quality standards to be increased accordingly. In addition, the teachers' ideas and education methods are of the highest priority. Therefore, teachers must learn to understand students' psychology and cultivate the overall quality of students in many aspects. They must not only pay attention to the accumulation of students' knowledge, but also must focus on students' thinking logic, expression skills and communication and innovation skills. Through the study of educational psychology, teachers can discover the characteristics and weaknesses of students, and gradually guide and inspire students to improve their ability to control their emotions and learn independently. Learning ability is the comprehensive ability of long-term accumulation of knowledge, interest, comprehension and patience, which therefore must be gradually improved through the guidance of educational psychology. In the process of learning educational psychology, teachers can gradually improve themselves, make their own educational methods be more scientific, enable themselves to grow gradually in long-term teaching and create their own innovative teaching methods so that they can improve students' overall mental quality and learning ability through teaching for a long time.

It can be said that students' learning and mastery of knowledge are the results of proper learning after they have obtained the correct learning methods.

\section{The Main Scope of Application of Educational Psychology in College Education}

To Understand the Psychological Status of Students. Students' interests and their desire for the outside world are the most important and the first motivation for learning. The environment, the communication environment, the life scene, the classroom environment and the laboratory environment can all arouse students' curiosity. Experienced teachers create interesting scenes in classrooms and laboratories, or create interesting environments by depiction, which will arouse students' interests in learning and spontaneously start active learning. In a good situation, students can be more immersed in learning, and the communication between them, including communication between teachers and students, and communication between students, are important possibilities for improving communication skills.

For students who are already bored with learning and the ones whose personality is too stubborn, criticism is meaningful, but it is impossible to make fundamental changes only by criticizing or venting teachers' anger. Therefore, students with different personalities must be treated in different methods to help students solve problems. Teachers must solve problems in a smart way. If they 
cannot learn to control their own emotions, they can control their emotions. The use of educational psychology and the implementation of methods of teaching students in accordance with their aptitudes are of great significance, which can help teachers to proactively reach out to students and understand students' psychological problems and the difficulties they face in learning so that they can prescribe the right medicine and help students to go one step further in superior places.

To Teach Learning Methods. The ultimate goal of education is to teach students how to learn, not to indoctrinize students with knowledge. As mentioned above, under normal circumstances, all students have the initial interest and motivation to learn, which is human instinct. But in the process of learning, students will inevitably encounter various difficulties. Therefore, in this case, they need the correct guidance of others, which does not only include the guidance of learning methods, but also includes psychological guidance in order to obtain more effective learning contents in a shorter period of time. This is also the basic responsibility of teachers. The educators' guidance must be organized, methodical and planned. Educators must understand how to make students develop skills and abilities. Theoretical knowledge and practical ability must be simultaneously improved, because they are mutually reinforcing. In addition, it is also very important to develop students' ability to study independently. The knowledge in the classroom is limited. If teachers can only give students a difficult task-based learning requirement at this time, students will tend to deal with fatigue and it is difficult to maintain their focus. Therefore, in the learning contents after class, teachers should master the common psychological conditions of each student in learning process and give students enough freedom to allow them to choose what they really are interested in within professional framework.

To Adjust the Psychological Quality of Teachers and Students. The control of students' psychological and emotional changes should not only be in the work of psychological counseling institutions on campus, but also should be in the classroom, and there must be a big premise that teachers must first understand the psychological conditions and emotional control ability of individuals with enough emotional intelligence through a certain amount of learning. Students are not single or mechanized in the process of learning. They need to face daily life and interpersonal relationships on campus, including the relationship between teachers and students and among students, which contains the combined effects of family factors and grades of individual learning, which may cause students' different levels of psychological stress. Although teachers have the responsibility of teaching students, not the one of psychological counseling for students. However, in the process of teaching, if they want to obtain good educational results, teachers must pay attention to students' psychological status to a certain extent.

Students who do not have a normal or healthy mental state can hardly continue to make progress in learning. Compared to students, teachers have a good social experience, a sound and stable psychological quality and a better understanding of the issues of communication in life. Therefore, communication has become a major issue in teaching process. Teachers need to strengthen communication with each student, actively and in a proper way to understand students' psychological states and emotional problems in communication, and give students emotional assistance and motivation in life and learning.

\section{The Main Problems Faced in the Current College Education and the Solutions with the Help of Educational Psychology}

The Status Quo of Learning of Students. Due to the long-term exam-oriented education, students have a tendency to lose their motivation and interests in learning after entering universities. Without the goal of exams or scores, it is easy for students to believe that the academic performance during college is not directly related to the working situation after graduation. In fact, this is a major problem caused by exam-oriented education. Students only take scores as a measure of their own goals. When they enter a workplace directly after graduation, they are often unable to adapt to work quickly. It will take a long time before they can accumulate experience to adapt to work. In fact, the scores reflect only a part of the knowledge, but in fact, after graduation, the theoretical knowledge is only a part, the professional ability will determine the real development in the future, because the 
workplace actually needs the ability, not memory of theoretical knowledge.

The free time of college students is much more concentrated than that of high school, which can lead to two possible influences. One is that the students who are lack of autonomy may only accomplish tasks during the course and spend other time in leisure and entertainment. One is that the students who have autonomous learning ability and the ones who are very interested in their own profession will be very active and do not only complete the tasks in the course, but also plan independently at free time. They also try professional-related work even during learning period, which may be very beneficial to students' future development.

If the teachers in charge of undergraduate courses in colleges and universities want their students to make achievements in learning process of 4 years or so and obtain very good teaching results, they must master the application of educational psychology state and consider students' psychology in different situations, taking students' autonomy as the most important consideration.

In the daily curriculum, in addition to accomplishing the task of imparting knowledge, teachers need to enhance communication with students and mobilize their learning autonomy through various methods. Only laying out simple tasks cannot achieve the desired teaching goals.

The Status Quo of Communication between Teachers and Students. The communication distance between teachers and students of colleges, especially during undergraduate periods, is relatively much further than that of high school period. In many professions and different subjects, the time that teachers interact with students is relatively short. As a result, communication between teachers and students has actually become somewhat difficult. However, educational psychology requires teachers to understand students' psychology and effective communication is the premise. Therefore, teachers need to learn more about students' learning status and mental state during the course and through network communication tools, establish an effective teaching relationship with students within a limited course time. In the teaching time of colleges and universities, teachers need to explore students' autonomous learning ability and should not be limited to limited teaching content. In the classroom, it is necessary to not only impart relevant professional knowledge, but also to strengthen the professional working experience as much as possible, and to introduce students to the possible self-directed learning direction in terms of professionalism. A fun and informative book list may sometimes result in greater teaching outcomes than what is taught in the course. Teachers should not only be the dissemination of professional knowledge in colleges and universities, but also should be the role model in the professional field. Their working experience is also very valuable to students and has inspiring knowledge and wealth.

Students who have entered the postgraduate study stage have already possessed a certain degree of professional knowledge, may have accumulated short-term professional working experience, have already had a stable psychological quality as a whole, and can reach a very good level in communication between graduate students and tutors. All professional postgraduate students will conduct one or more research projects with the tutor during their studies. At this time, the theoretical knowledge is still important, but the overall focus of graduate students has entered the practice of laboratory, workplace or other working sites. Participation in practice is also very beneficial to the progress of knowledge for graduate students in academic direction. In such an environment of working together, the graduate student tutor is more of an instructor of experience, and a method of working and a method of learning. Under the guidance of educational psychology, the tutor needs to understand the learning and psychological conditions of each student and conduct appropriate guidance. However, in this learning stage, the tutor should minimize the restrictions on students after giving students the correct research direction and inspire students' innovation consciousness.

Internship. Internship is an important indicator of college teaching. Many professional students will be required to perform internships for a period of time during the learning process. This stage is very important for students. It is the preparation for entering the work and entering the society during learning. An effective internship can help students understand the long-term learning contents supported by interest, including how to transform knowledge into work in the society, how to transform them into productive forces, what kind of communication students have with their 
superiors and their subordinates and what they need to master in their work beyond the expertise and skills. However, most students will face different degrees of discomfort in workplace after graduation, which requires a certain degree of psychological quality. This psychological quality must be involved in college education before students enter the workplace. Therefore, not paying attention to students' psychological quality training on campus is a serious problem that can easily bring about delay. Teachers should give certain professional support and psychological support during students' internship, actively train students how to solve the psychological problems facing the society, and immediately follow up students' psychological state during the internship. Through such a period of time, students who practice effectively will not only gain working experience, but will also go a step further in their understanding of the nature of their profession.

\section{Conclusion}

In general, the teacher's job is to maximize the learning results of students through various means within their working hours. Therefore, teachers should not only master their own knowledge or rely too much on unilateral teaching. They must actually consider the acceptance of students and the individual's progress in learning ability. The college teachers' study and use of educational psychology can effectively solve the problems in students' acceptance of knowledge. Through the control of emotion and psychology, students can develop comprehensively and achieve the best teaching results.

\section{References}

[1] Pan Yu. Education Psychology [M]. Beijing: People's Education Press, 1980.

[2] Gui Shichun. Psycholinguistics [M]. Shanghai: Shanghai Foreign Language Education Press, 1985.

[3] (United States) Robert Sleven. Lv Hongmei, Yao Meilin etc. Translation. Educational Psychology: Theory and Practice [M]. People's Posts and Telecommunications Press, 2016.

[4] Ma Lin. Integrating knowledge of psychology to promote innovation of college counselors' work methods [J]. Chinese national conditions, 2010 (01).

[5] Zhang Dajun. Psychology Library 21 - Educational Psychology [M]. Kaiming Press, 2012.

[6]Shi Liguo. Innovative research on college teaching theory and practice [M]. Beijing Institute of Technology Press, 2014.

[7] Li Jinzhen, Wang Wenzhong, Shi Jiannong. Positive Psychology: A New Direction of Research [J]. Advances in Psychological Science, 2003 Issue 3.

[8] Qi Yongqin. Innovation Education and Experimental Teaching Reform in Colleges and Universities [J]. Laboratory Research and Exploration, No. 3, 2002

[9] Chen Qi. Contemporary Educational Psychology [M]. Beijing Normal University Press, 2009.

[10] Fan Zhifen, Qi Peng. The Application of Psychology-related Knowledge in Ideological Education of Colleges and Universities [J]. Value Engineering, 2010 Issue 5. 